\title{
Permanent Magnet Generators for Renewable Energy Devices with Wide Speed Range and Pulsating Power Delivery
}

\author{
David G Dorrell \\ Department of Electronics and Electrical Engineering, \\ University of Glasgow, Glasgow, UK \\ E-mail: d.dorrell@elec.gla.ac.uk
}

\begin{abstract}
This paper describes the design of a direct-drive permanent-magnet generator for use in a novel sea-wave electrical generator. The basic system is briefly described and the target specification derived from the device and the wave tank performance. The design for the brushless permanent-magnet generators is then developed using SPEED PC-BDC and verified using finite element analysis (PC-FEA). A diode bridge model is also tested using Portunus system simulation.
\end{abstract}

Keywords: Permanent Magnet Brushless Generator, Renewable Wave Energy

Reference to this paper should be made as follows: Dorrell, D. G. (2008) 'Permanent Magnet Generators for Renewable Energy Devices with Wide Speed Range and Pulsating Power Delivery', Int. J. Computer Applications in Technology, Vol.

\section{INTRODUCTION AND SYSTEM SPECIFICATION}

Power delivery in renewable energy systems can be very erratic. The power can vary over a large range (for instance wind turbine generators); and also in some applications the power can be delivered in a cyclic manner over a period of several seconds (for instance sea wave power delivery - a simple system is described by Dorrell et al, 2006).

In this paper a small-scale prototype wave device is briefly described and used to specify the load demands on the device generators. This specification is then used to design direct-drive permanent-magnet generators that may be suitable for this application and the system is simulated. This is as an alternative to the geared system that has been fitted. SPEED software from The University of Glasgow (Miller, 2006) is used in this procedure (PC-BDC for analytical design and PC-FEA for electromagnetic finite element analysis for simulation verification). Loading effects are investigated and the performance using $q$-axis current control and diode bridge rectification is assessed. A software package Portunus is used to assess the diode bridge operation.

\subsection{Power from Waves}

Wave motion is caused by winds blowing across the surface of the sea. These cause the water to move in a circular motion where the radius decreases with increasing water depth. Phase differences in the water particles produce the propagating waves. If a floating body is put into the water then this will move in an orbital motion with the wave. The power per unit length of wave front in the waves (Shaw, 1982) can be expressed as

$$
P=\frac{\sigma g^{2} H^{2}}{32 \pi f}=\frac{981.2 H^{2}}{f}=981.2 H^{2} T \quad \mathrm{~W} / \mathrm{m}
$$

where $H$ is the wave height and $T$ is the wave period. If a cylinder is placed into the water and moved in a circular motion then it will generate waves that propagate in one direction only away from the cylinder. Conversely, if waves propagate towards a cylindrical body and this body is controlled in an appropriate fashion so that it rotates then it should absorb energy from the waves. This was investigated by Evens et al, 1979 and the device was called the Bristol Cylinder. 


\subsection{Bristol Cylinder Prototype and Wave Tank Specification}

A prototype is being developed and this is shown in Figure 1. The armature arrangement at each end of the cylinder is attached to an internal generator. In the prototype the shaft is connected to a geared arrangement (1:10 set-up) and a modified permanent-magnet motor (which is utilized as a generator) as shown in Figure 2. However it has been suggested that a more satisfactory arrangement is to use bespoke direct-drive generators in the device and this paper describes the design of these.

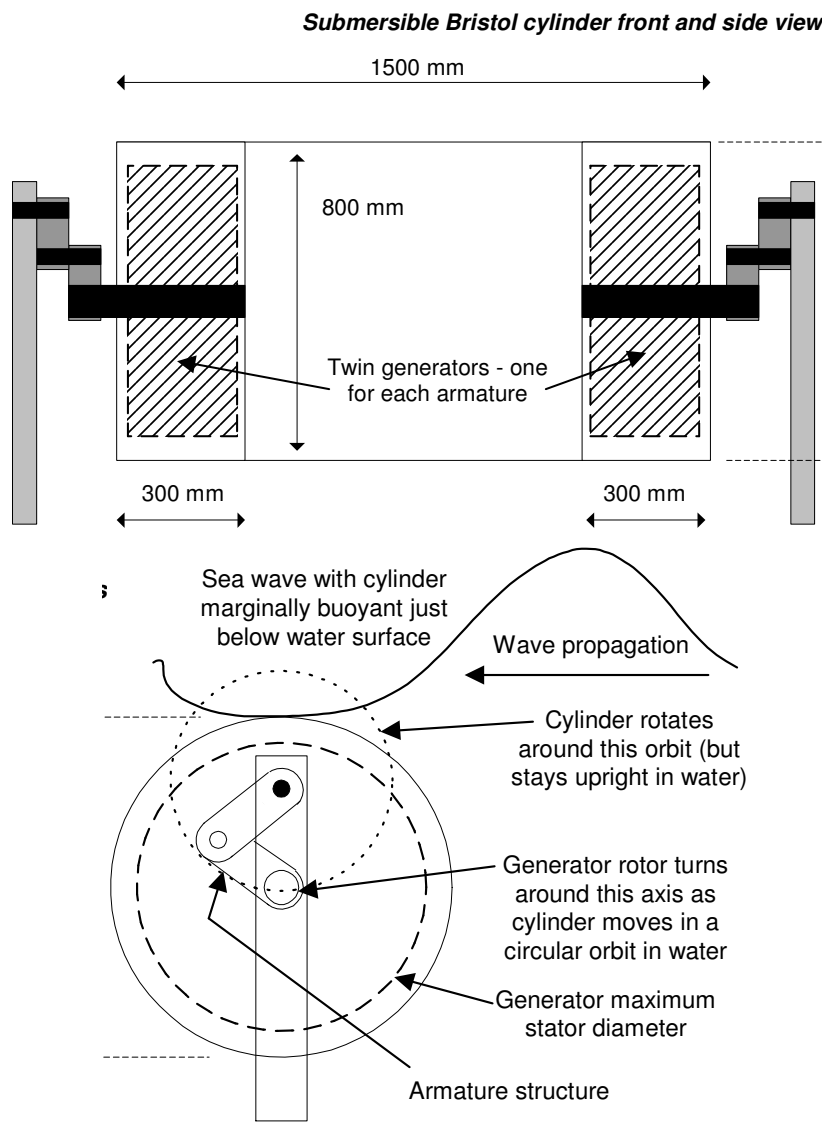

Figure 1 Front section and side section of the prototype machine

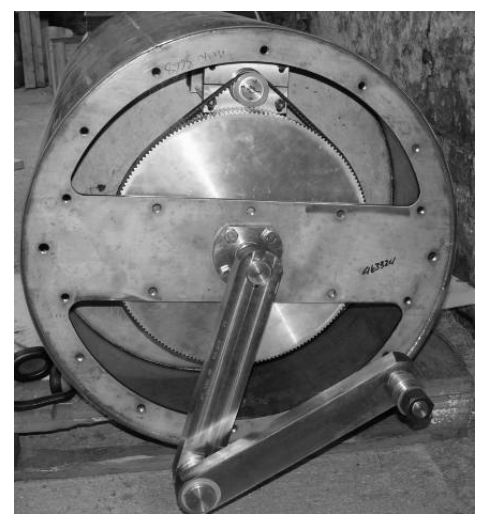

Figure 2 Manufactured machine with geared PM machine

For a small-scale prototype such as this then $25 \%$ conversion would be considered as being high. The wave- tank maximum wave-heights were the device is to be tested are given over a frequency range in Figure 3. If we assume $25 \%$ conversion and also that the device rotates at the same frequency as the waves then the torque requirements for each generator are shown in Figure 3. This is quite peaky around 3 second wave period, therefore $200 \mathrm{Nm}$ is taken as a maximum since this is very low speed. From Figure 1 the outer diameter of the generator should be less than $760 \mathrm{~mm}$ with an axial length (including windings) of $270 \mathrm{~mm}$. The lowest period at $200 \mathrm{Nm}$ is about 4 seconds which corresponds to $15 \mathrm{rpm}$. This is very low speed - even compared to direct-drive wind turbines. Below this speed the torque requirement decreases.

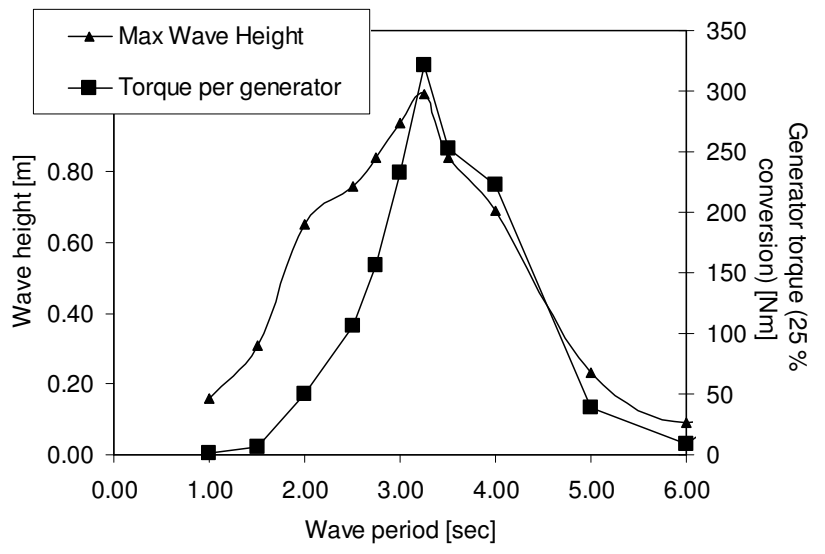

Figure 3 Maximum wave power across frequency range of wave tank and required torque at $25 \%$ conversion

\section{GENERATOR DESIGN}

In this section the machine is sized using basic sizing techniques and geometric parameters. A PC-BDC model is developed and simulated. It is then tested using PC-FEA for performance accuracy and cogging torque.

PC-BDC is an example of the latest computer aided design software for brushless permanent-magnet machines. The software uses analytical magnetic circuits to analyse the machine design problem. The geometrical, material and control data is entered via a spreadsheet and the output data takes the form of output spreadsheets and graphical representations (Miller, 2006). Data can also be output on to clipboards for manual transfer to Microsoft Excel or Word, etc. The software can also be called up using ActiveX so it can also be used as a "blackbox" calculation tool where it can be called (for example) from MATLAB or Microsoft VB. It can then be combined with other packages (for instance, thermal design packages as illustrated by Dorrell et al, 2006).

PC-FEA is a finite element analysis (FEA) package that is a "bolt-on" to the other SPEED packages (e.g., PC-BDC) and it uses the geometrical, material and control data, via a linking routine (called a Gofer), to construct a 2-D model of the machine model and obtain a set of solutions for various problems such as back-EMF under no load, current/flux- 


\section{DELIVERY}

linkage loops for torque calculation under load, and cogging torque. There are many other routines too. This represents a very time-effective way of obtaining finite element solutions since there is no need to spend long periods developing meshes and setting control strategies.

\subsection{Specifying and Sizing}

If the target speed is $15 \mathrm{rpm}$, allowing a frequency of 12.5 $\mathrm{Hz}$ at this speed, gives a pole number of 100 . The frequency is low because the generator may be required to operate at higher speed (above $60 \mathrm{rpm}$ ) and also the pole number would be prohibitively high. Hendershot and Miller (1995) suggest that the torque per rotor volume (TRV) for a highperformance servo machine should be between 20 and 45 $\mathrm{kNm} / \mathrm{m}^{3}$. Since this is a prototype permanent magnet machine (using sintered neodymium magnets) then the low end of the range is taken. The total axial length for the machine is $270 \mathrm{~mm}$ and often the core length of a machine is about half the total length. Using this length gives a rotor diameter of

$$
\begin{aligned}
D & =2 \sqrt{\frac{T}{T R V} \times \frac{1}{\pi L_{s t k}}} \\
& =2 \times \sqrt{\frac{200}{20 \times 10^{3}} \times \frac{1}{\pi \times 0.135}} \\
& =0.307 \mathrm{~m}
\end{aligned}
$$

Hence, the radius of the rotor it $150 \mathrm{~mm}$ and the axial length is $135 \mathrm{~mm}$. Surface magnets are used to prevent saliency and minimize $X_{q}$. The machine will be 3-phase. A simple 3 coils-per-pole could be set which would be 3 slots per pole. The problem with this is that there is likely to be substantial cogging torque and also 300 slots is a complicated and difficult geometry to realize. The sizing is calculated to fill the generator voids in Figure 1. It is aimed to easily meet the performance so that it can be connected to a diode bridge rectifier (requiring low armature reactance) and give good efficiency. The problems with compact generator design were discussed by Dorrell (2007).

\subsection{Slot Choice, Winding Layout and PC-BDC Model}

The slot number should be a multiple of 3 for the 3-phase winding. A convenient number for 100 poles is 90 slots with two coil-sides per slot. There are 30 coils per phase and each coil would be one tooth pitch. There is an alignment every 9 slots (or 10 poles) so that the coils can be grouped in 3 coils per grouping. Figure 4 shows the coil arrangement (taken from the PC-BDC Winding Editor). The slots and stator are scaled to give appropriate slot area $\left(211 \mathrm{~mm}^{2}\right)$, tooth width $(4 \mathrm{~mm})$ and yoke depth $(30 \mathrm{~mm})$. This is shown in Figure 5 which is taken from the PC-BDC Outline Editor. The outer radius is only $420 \mathrm{~mm}$ which is much less than the cylinder void.

The slot opening was set to $3 \mathrm{~mm}$ and the coils consist of 60 series turns and each turn is formed from two parallel stands of $0.75 \mathrm{~mm}$ diameter wire. The gross slot fill is 0.5 . This represents a winding that can be easily realised when manufacturing prototype machines by non-specialist winding technicians.

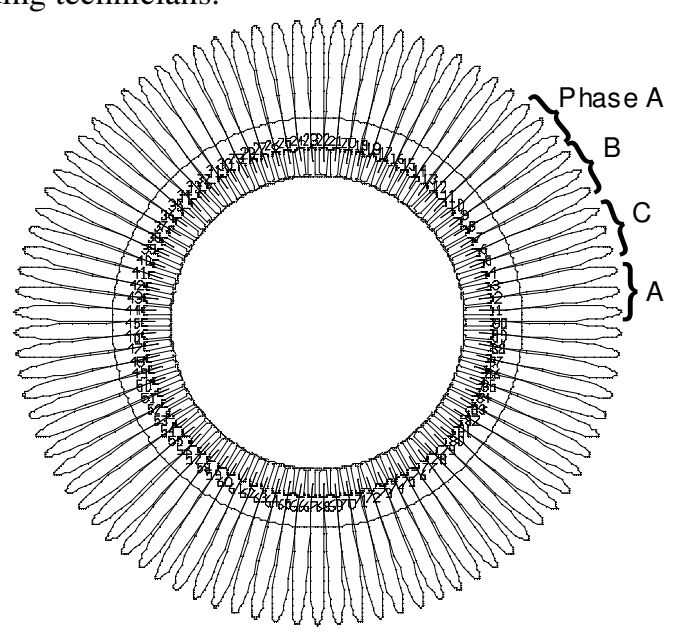

Figure 4 Machine winding arrangement
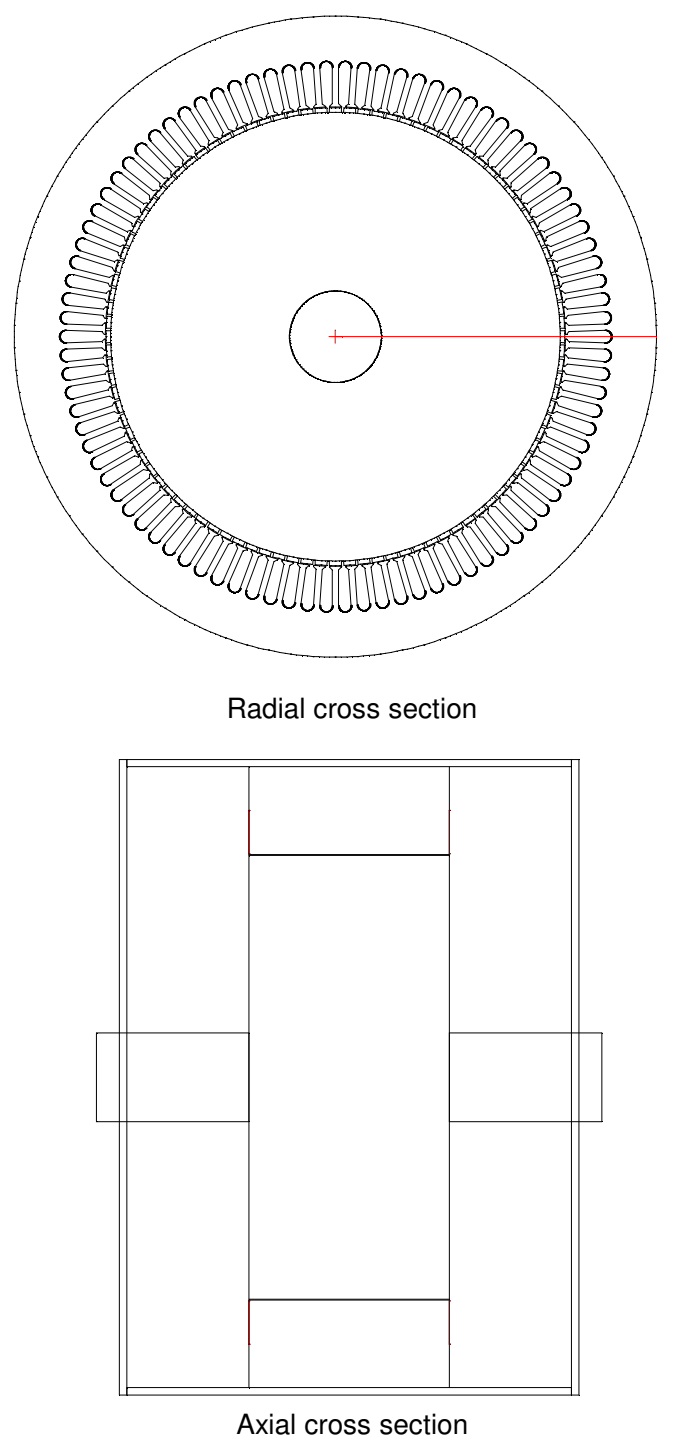

Figure 5 Machine geometrical topology 
The magnets are rare-earth type with a $B_{r}$ of $1.1 \mathrm{~T}$. The thickness was set to $3 \mathrm{~mm}$ with a pitch-per-pole of 150 electrical degrees. The thickness of the magnet can be crucial. If they are too thin then there will be high armature reactance and poor regulation. If they are too thick then this is quite wasteful in magnet material. Dorrell (2007) discussed this issue.

At $228 \mathrm{Nm}$ (generating) the current is only $1.77 \mathrm{~A} \mathrm{rms}$ (with an induced back-EMF of $68 \mathrm{~V}$ ). This gives a winding current density of $2 \mathrm{~A} / \mathrm{mm}^{2}$. This is very low; however, it is necessary to do this to maintain a good efficiency (70\%). While brushless permanent-magnet motors are known to operate at efficiencies of $90 \%$, this is for a machine operating at maybe $100 \mathrm{~Hz}$ supply frequency. There is a trade-off here where the operating frequency is low to limit the pole number. For instance, if the speed is doubled to 30 rpm ( $25 \mathrm{~Hz}$ operation) for the same torque then there would be a small increase in iron loss but the copper loss is about the same. The generated power is therefore doubled for the same current (i.e., the efficiency increases to about $85 \%$ ). Hence low-loss windings are essential for efficient operation in low-frequency high-pole number machines.

\section{SIMULATIONS, FINITE ELEMENT ANALYSIS AND COGGING TORQUE}

In this section further PC-BDC simulations are put forward together with PC-FEA simulations to investigate the current/flux-linkage loop (I-Psi diagram) - this is used to cross-check the torque. This is obtained by rotating the rotor and current vector together in the FEA, obtaining a number of simulations at set positions. The area enclosed in the loop represents the work done and hence the torque can be obtained. This is the method used to obtain torque in a switched reluctance machine but it can be applied to any machine in general.

The cogging torque is also examined using PC-FEA. This is done by stepping round one rotor pitch using small steps and obtaining the torque from the FEA when the stator windings are unexcited. Care has to be taken with this simulation because cogging torque is susceptible to numerical error and variation. Several torque calculation methods were reviewed by Dorrell et al (2006).

Finally the system is simulated using Portunus (which is a circuit and power electronics simulation package). This is carried out to investigate the performance of the machine when attached to a diode bridge rectifier rather than a controlled rectifier where the current is kept on the $-q$-axis.

\subsection{PC-BDC simulation and Phasor Diagram}

Fig 6. shows the back-EMF, current and torque from PCBDC. The machine is current fed and the current phasor is on the $-\mathrm{q}$ axis. The phasor diagram is also shown in Figure 7. When the machine is attached to a diode bridge rectifier the performance will be degraded, this is because the current will not be in phase with the back-EMF and not sinusoidal.
Low $I_{q} X_{q}$ will help the diode bridge performance and this is investigated later.

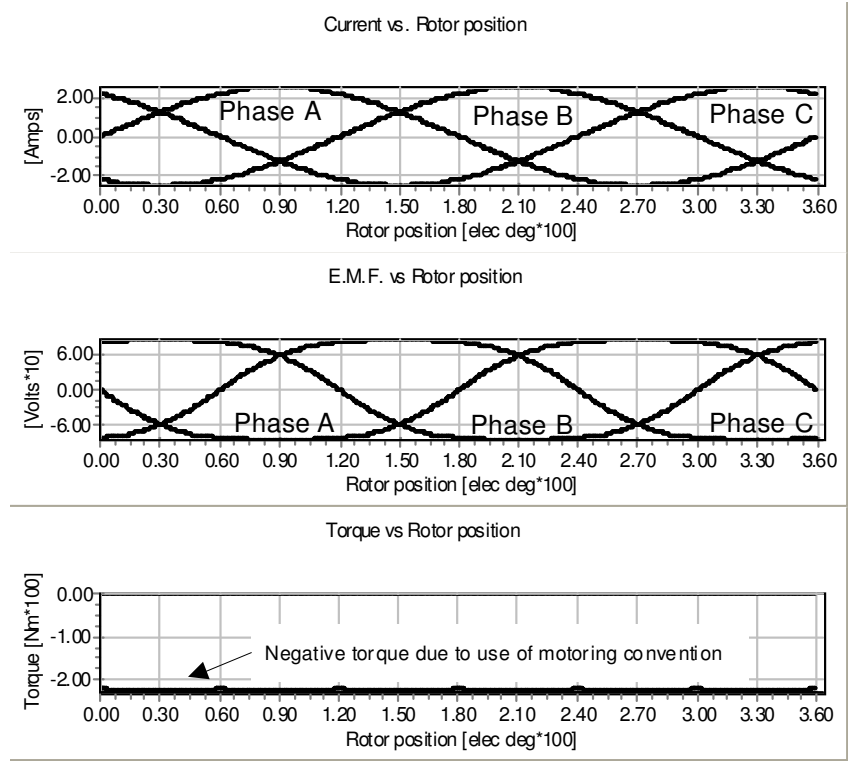

Figure 6 Current, back-EMF and torque waveforms

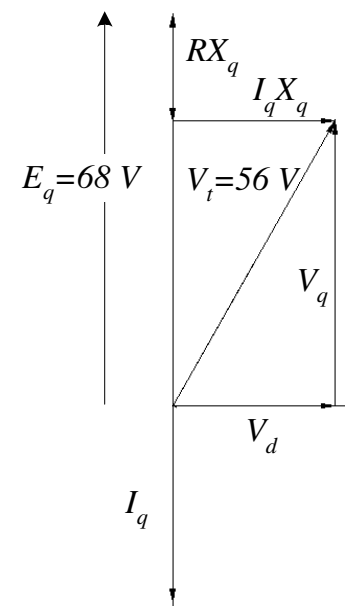

Figure 7 Phasor diagram with current on -q-axis

\subsection{Finite Element Analysis and I-Psi Diagram}

The PC-BDC model was fed through to the finite element bolt-on package PC-FEA in the SPEED software. The model spanned 10 poles and a flux plot is shown in Figure 8 for this segment. This shows that the machine is not heavily fluxed so that it will have low iron losses.

The derived current/flux-linkage loop is shown in Figure 9. This is similar to the loops used in switched-reluctance machines as mentioned earlier. The current and rotor rotation are cycled round together and the flux linkage measured at each step. The area enclosed is the work done and therefore, with a knowledge of the rotor speed, the torque can be calculated in a straightforward manner. If the loop is long and thin then the machine is operating poorly however this example shows good conversion. These loops are calculated both in PC-BDC (solid line - torque $=222$ $\mathrm{Nm}$ ) and PC-FEA (dotted line - torque $=254 \mathrm{Nm}$ ). Good correlation is illustrated showing the validity of the 


\section{DELIVERY}

analytical magnetic circuits in PC-BDC even with a design with many poles and a fractional slot number such as this.

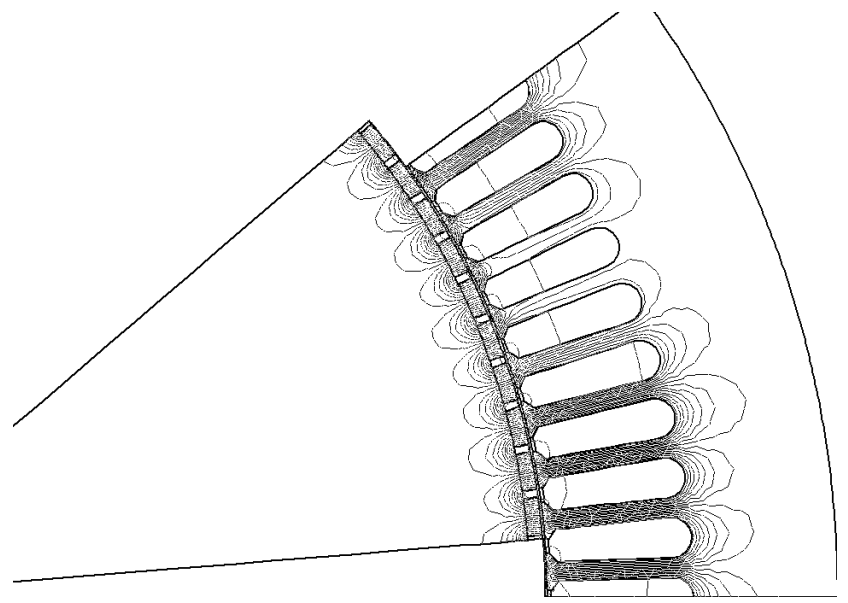

Figure 8 One solution for FEA model

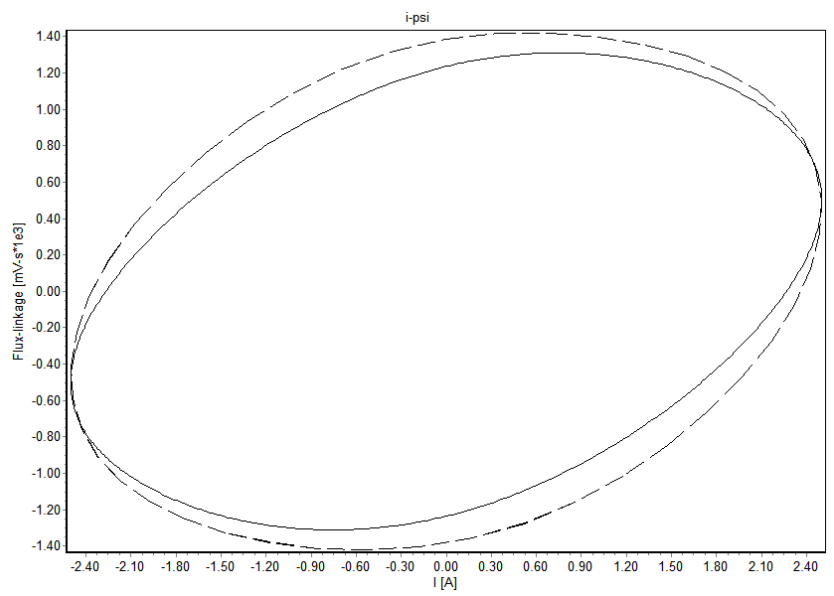

Figure 9 I-Psi loop for one phase (dotted - PC-FEA, solid - PC$B D C)$

\subsection{Cogging Torque Calculation from PC-FEA}

The cogging torque Gofer in PC-BDC was used in this exercise to produce a PC-FEA model and simulation. Cogging torque requires fine detail of the machine magnetic circuit to calculate an accurate model, particularly when there is not an integral number of slots per pole, as is the case here. This routine steps around the rotor and measures the cogging torque using a variety of methods. Cogging torque is very susceptible to numerical error so it is important to use these different methods to see if the calculation is valid. The calculation is also prone to errors due to poor meshing and Figure 10 show the mesh used in this instance. The air-gap has four regular layers and the shape of these do not change during the rotation - the distance between the nodes round the central air-gap boundary is equal to the step angle between steps. Figure 11 also shows the cogging torque calculation from the virtual work method. The other methods correlated with this and it can be seen that there is a cogging torque of about $2.8 \mathrm{Nm}$ peak to peak.

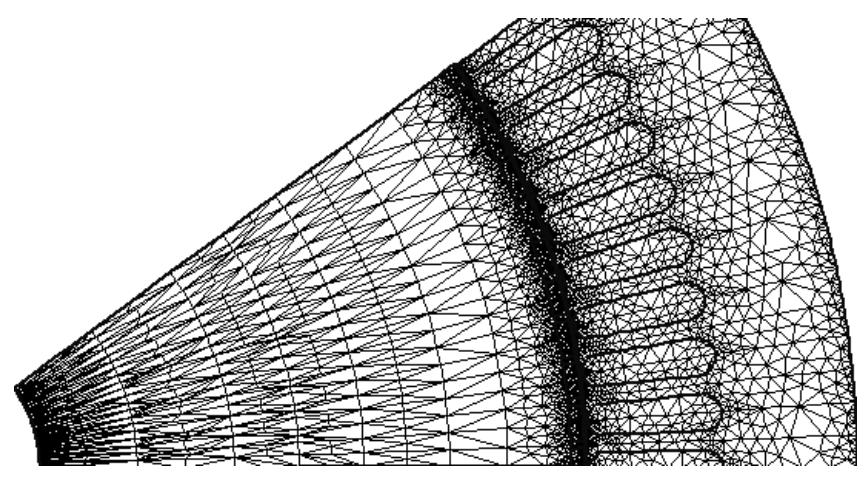

Figure 10 Mesh used in cogging torque calculation

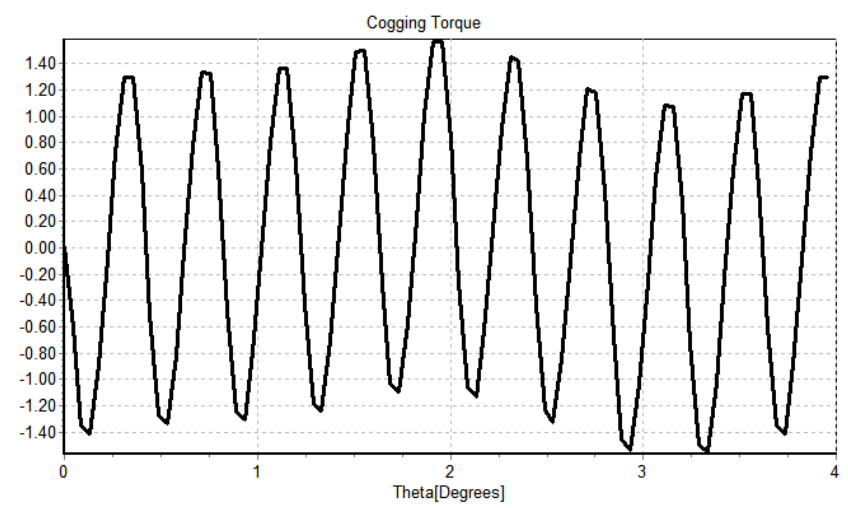

Figure 11 Cogging toque characteristic over rotor cycle

\subsection{Diode Bridge Operation}

While the latest version of PC-BDC incorporates diode bridge operation it was decided to use a specialist circuit analyzer package to simulate the machine when attached to a diode bridge. The back-EMF, phase resistance and phase inductance can be extracted from PC-BDC and used in a system simulation of the machine in operation with a diode bridge. There are several circuit simulators available and here Portunus is used in a similar manner to Dorrell (2007). The circuit is shown in Figure 12. The back-EMF waveforms in Figure 6 show that it is not a bad approximation to assume that they are sinusoidal; if further refinement is required then harmonic voltage sources can be put into the circuit as illustrated in Dorrell (2007).

The simulation in the previous sections has an output power which is obtained from

$$
\begin{aligned}
P_{\text {out }} & =3 E_{q} I_{q}-3 I_{q}^{2} R_{p h} \\
& =3 \times 68 \times 1.77-3 \times 1.77^{2} \times 10.6 \\
& =261.3 \mathrm{~W}
\end{aligned}
$$

where the current is on the $-q$ axis so that the there is unity power factor between $E_{q}$ and the current. Iron loss is neglected.

However, using a diode bridge means that the current is no longer confined to the $-q$ axis and the simulation waveforms under these conditions are shown in Figure 13. The output power is found to be about $220 \mathrm{~W}$. This fits in with the results in Dorrell (2007) which suggests that an output power reduction to about $80 \%$ when moving from $q$-axis current control to diode bridge rectification with a 
generator of reasonably low armature reactance. The load resistor can be adjusted to vary the output power and 30 ohms is used here.

For commercial system, the DC voltage of the output stage of the diode bridge would be controlled using a chopper. The chopper output would be stabilized by connection to a DC link and a battery/inverter combination of some sort. This is a somewhat more straightforward system than using a fully-controlled rectifier with position feedback to maintain $-q$-axis control, and would minimize the instrumentation needed for the generator.

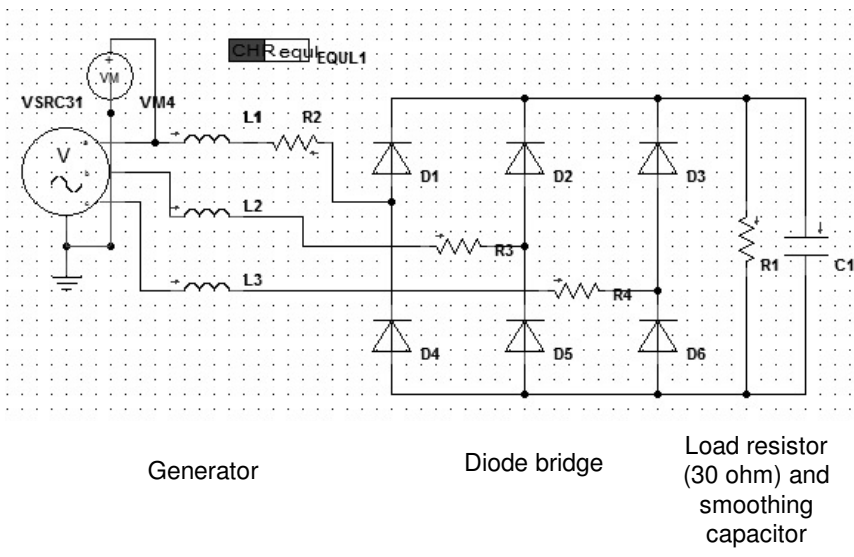

Figure 12 Portunus system simulation

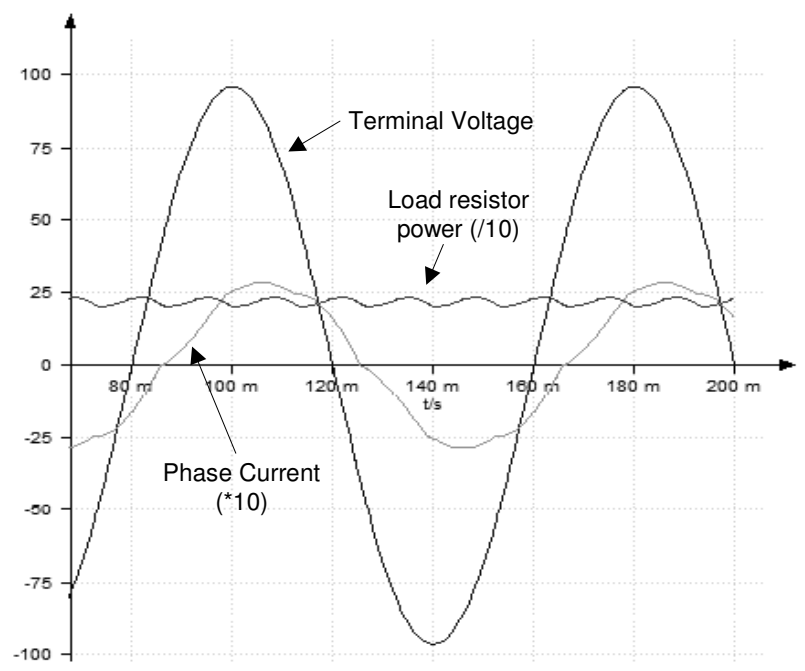

Figure 13 Waveforms with diode bridge rectifier load

\section{CONCLUSIONS}

This paper has outlined the design procedure for a directdrive permanent-magnet generator for use in a small wave generator prototype. The application was described in the first part of the paper as an example of a renewable energy system that is currently under development. It requires a very low speed and a high pole number generator design if a direct-drive arrangement is adopted.

The steps that were carried out to verify the design were described (using different software packages and techniques). The software used represents the latest and most sophisticated electrical machine design packages currently available and it illustrates that, with these tools, machine design (whether it motor or generator design) can be carried out without the need for complicated manual design calculations or time-consuming FEA model development.

The design is found to meet the application requirements with capacity to spare. The reason for needing this is because of the pulsating nature of the power delivery.

\section{REFERENCES}

D. G. Dorrell M.-F. Hsieh and W. Fillet. Segmented small oscillating water columns using in-line Savonius rotors. Proceedings of the International Offshore and Polar Engineering Society Meeting (ISOPE), Lisbon, Portugal, (on CD), 2007.

T.J.E. Miller. SPEED's Electrical Motors. SPEED Laboratory, University of Glasgow, 2006.

R. Shaw, Wave Energy: A design challenge, Ellis Horwood Publishers, 1982.

D. V. Evans, D. C. Jeffrey, S. H. Salter, and J. R. M. Taylor. Submerged cylinder wave energy device: theory and experiment. Applied Ocean Research, Vol. 1, pp. 3-12, 1979.

D. G. Dorrell, D. A. Staton and M. I. McGilp. A Combined Electromagnetic and Thermal Approach to the Design of Electrical Machines. ICEMS, Nagasaki, Japan 20-23 Nov 2006.

J. R. Hendershot and TJE Miller. Design of Brushless permanent Magnet Motors. Magna Physics Publishing and Clarendon Press, Oxford, 1994.

D. G. Dorrell. Design Requirements for Brushless Permanent Magnet Generators for Use in Small Renewable Energy Systems. Proceedings of IEEE Industrial Electronics society Annual Meeting (IECON), Taipei, Taiwan, (on CD), 2007.

D. G. Dorrell, M. Popescu and M. I. McGilp. Torque Calculation in Finite Element Solutions of Electrical Machines by Consideration of Stored Energy. IEEE Transactions on Magnetics, Oct. 2006.

\section{Biographical notes:}

D G Dorrell obtained his PhD from The University of Cambridge, UK, in 1993. He has held lecturing positions with The Robert Gordon University, UK and The University of Reading, UK. He is currently a Senior Lecturer with The University of Glasgow, a post he has held since 2001. He is also an Adjunct Associate Professor with the National Cheng Kung University, Taiwan and has visited several other institutes in recent years. His research areas cover electrical machine design and analysis and also renewable energy applications. He is a Chartered Engineer in the UK and a Fellow of the IET, London. He is also a Senior Member of the IEEE, USA. 